\title{
CFD ANALYSIS ON INVELOX, A NEW CONCEPT IN WIND POWER
}

\author{
Vinay C D ${ }^{1}$, S S Desai ${ }^{2}$, P S Kulkarni ${ }^{3}$ \\ ${ }^{1}$ P G Student ${ }^{2}$ Professor Emeritus Dept. of Mechanical Engineering, Siddaganga Institute of Technology, Tumakuru, \\ Karnataka, India. (vinaycd7@gmail.com,drssdesai43@gmail.com) \\ ${ }^{3}$ Professor, Dept. of Aerospace Engineering, Indian Institute of Science, Bengaluru, Karnataka, India.
}

\begin{abstract}
This study focuses on understanding the physics of fluid flow in and around the INVELOX delivery system. Enhancing the capability of existing system to capture more amount of air by modifying the inlet configuration is the aim of this work. CFD analysis and validation with the experimental results has been done. Different inlet configurations have been studied and results are promising for generating more wind power as compared to earlier the configuration.
\end{abstract}

Keywords: Wind Power, Sustainable Energy, Speed Ratio, Structured Mesh, CFD, Fluent.

\section{INTRODUCTION}

INVELOX stands for INcreased VELOcity. A new concept in utilizing the low speed wind is defined. INVELOX is the innovation of Daryoush Allaei supported by SHEERWIND in developing and installing for experimental purpose. INVELOX consists of 5 main parts; 1) Intake with guide blades 2) Double nested cone (Wind channeling) 3) Wind Concentrator 4) Venturi and wind power conversion system 5) Diffuser.

Free stream wind is directed by the intake section due to its geometrical features into the tapered double nested cone where the wind is channeled. Further the wind is directed into the wind concentrator, due to reducing cross section at the Venturi wind gets naturally accelerated where the wind turbine is placed and power is extracted. Air is allowed to the environment by the diffuser safely. The magnification of wind velocity is defined by the term speed ratio. Speed ratio is the ratio of average velocity of wind at the Venturi cross section to the free stream wind speed.

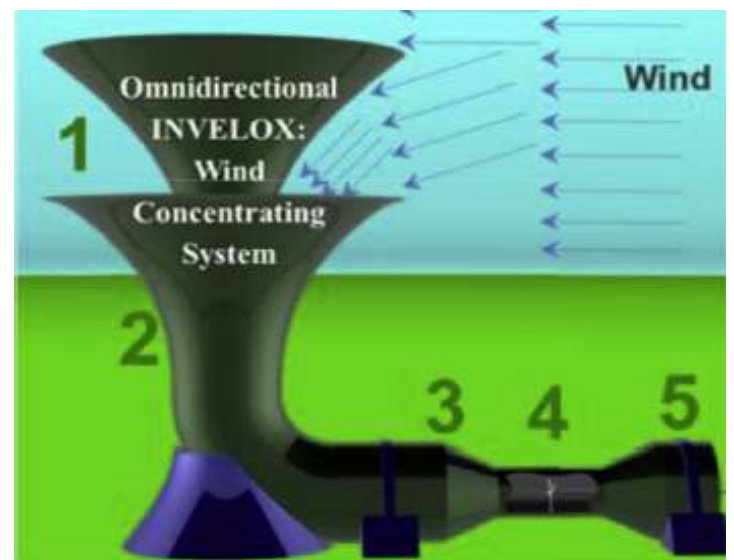

Fig. 1 - Schematic of INVELOX 1) Intake 2) Wind Channeling 3) Wind Concentrator 4) Venturi plus Wind Power Conversion System 5) Diffuser
Key features of this system are; 1) Decoupling of intake and the turbine. So that turbine can be installed based upon requirement and environmental conditions 2) Installing the wind turbine at ground reduces $\mathrm{O} \& \mathrm{M}$ costs 3) Decoupling allows to design the system for higher speed ratio 4) Smaller blades result in savings in material, manufacturing, transportation, and installation 5) No need for rotating the intake as the system is omnidirectional, thus it's a static structure 6) Power rating of $500 \mathrm{~W}$ to $25 \mathrm{MW}$ can be designed.

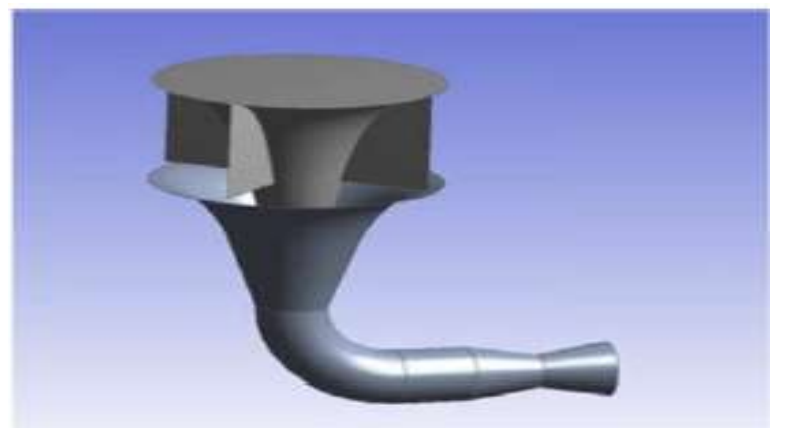

Fig. 2 - INVELOX with 4 Guide Blades

INVELOX can overcome the problems faced by traditional wind turbines such as; 1) Visual impact 2) High cut-in speeds 3) Distance from grid 4) Icing 5) Turbine reliability 6)Impact on wild life such as birds.

The objectives of the present work are:

$>$ Understand the physics of fluid flow inside the INVELOX.

$>$ Check the effectiveness of the system under various free stream wind speeds.

$>$ Check the omnidirectional property of the system.

$>$ Validate the computational results with the experimental results.

$>$ Try and modify the inlet configurations to improve the amount of air captured i.e., to increase the mass flow rate in wind duct. 


\section{PROBLEM DESCRIPTION:}

Control volume analysis for conservation of mass, axial and angular momentum balances, and energy conservation for inviscid, incompressible axisymmetric flows yields:

$\oint_{\mathrm{A}} \rho \cdot \mathbf{V d} \mathbf{A}=0$

$\oint_{A} u_{x} \rho \mathbf{V} \cdot d \mathbf{A}=T-\oint_{A} \rho d A \cdot \mathbf{e}_{\mathbf{x}}$

$$
\begin{gathered}
\oint_{A} \mathrm{ru}_{\theta} \boldsymbol{\rho V} \cdot \mathrm{d} \mathbf{A}=\mathrm{Q} \\
\oint_{\mathrm{A}}\left[\frac{\mathrm{p}}{\rho}+\frac{1}{2}\left\|\mathrm{~V}^{2}\right\|\right] \rho \mathbf{V} \cdot \mathrm{d} \mathbf{A}=\mathrm{P}
\end{gathered}
$$

Where $\mathrm{V}=\left(u_{x}, u_{r}, u_{\theta}\right)$ is the velocity vector in the axial, radial, and azimuthal direction respectively; $r$ is the radius; $\rho$ is the density of air; A denotes the outward-pointing area vector of the control surface; $e_{x}$ is the unit vector in the $x$ direction; $\mathrm{p}$ is the pressure; $\mathrm{T}$ is the axial force (thrust) acting on the rotor; $\mathrm{Q}$ is the torque; and $\mathrm{P}$ is the power extracted from the rotor.

It is obvious from the above relation that the extracted wind power $\mathrm{P}$ can increase by increasing the mass flow rate $\oint_{A} \rho . \boldsymbol{V} d \boldsymbol{A}$ or the total energy drop $\mathrm{e}=\left[\frac{P}{\rho}+\frac{1}{2}\left\|V^{2}\right\|\right]$ across the turbine.

The increased mass flow rate carries energy per unit mass from the free stream given by $\mathrm{e}=\left[\frac{P}{\rho}+\frac{1}{2} V^{2}\right]$ which for inviscid fluids remains unchanged till it interacts with the turbine in the Venturi section.

INVELOX passively converts the existing kinetic and potential/ pressure energy of wind to higher kinetic energy $\frac{1}{2}\left\|V^{2}\right\|$ that can more effectively be converted to mechanical rotation of a turbine. Along any part of the INVELOX tower of constant cross-section the velocity remains the same and therefore there is no kinetic energy drop across the turbine. Thus, the extracted power is given by $\mathrm{P}=$ $\oint\left(\frac{P}{\rho}\right) \rho \boldsymbol{V} \cdot \boldsymbol{d} \boldsymbol{A}$ which can be approximated by the $\mathrm{P}=\eta \mathrm{Q} \Delta \mathrm{P}$, where $\mathrm{Q}$ is the increased volumetric flow rate, $\Delta \mathrm{P}$ is the pressure drop across the turbine and $\eta$ is its efficiency.

\section{EXPERIMENTAL DATA}

INVELOX was fielded and experimented by SHEERWIND. 4 guide blade configuration was studied i.e. intake consists of 4 guide blades placed symmetrically around the upper cone. The data obtained from the experiments showed that the speed ratio varies between to 1.5 to 2.1. Two cases were tested, one without placing the turbine and another with turbine. In both the cases the data was similar and it was calculated that for velocity of $6.71 \mathrm{~m} / \mathrm{s}$ the speed ratio has to be around 1.8. Thus all the simulations in the present work are made for free stream velocity of $6.71 \mathrm{~m} / \mathrm{s}$.

\section{MODELLING AND GRID GENERATION:}

Planar model is created in SOLIDWORKS according to the dimensions shown in the figure. External domain of size $140 \mathrm{~m} \times 100 \mathrm{~m} \times 70 \mathrm{~m}$ is chosen. Hybrid mesh is adopted. Structured mesh is generated for fluid domain inside the INVELOX and for external domain unstructured mesh is generated. And to reduce the meshing complexity and time whole system was divided in to 4 parts namely; 1) Wind Capturer 2) Bottom cone 3) Wind carrier and accelerator 4) External fluid domain. All this parts are meshed separately and interface is given in fluent between them.
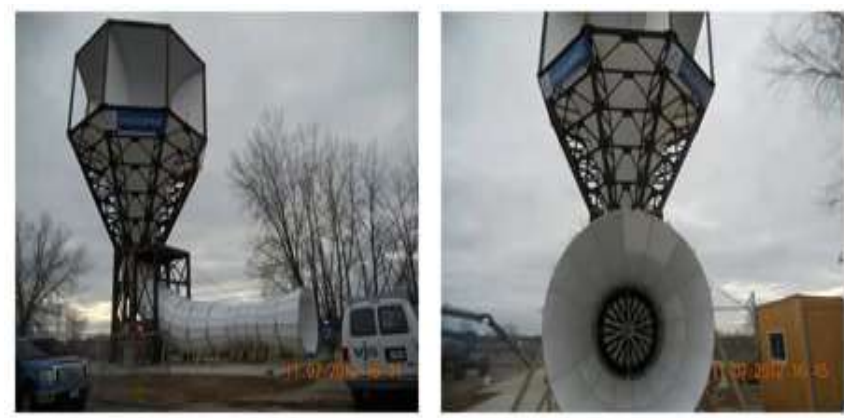

Fig. 3 - Fielded INVELOX at Chaska, Minnesota

Since the objective of this study is to try and test different inlet configurations only the capturer part can be modeled, meshed and replaced in fluent instead of modeling and meshing all the parts.
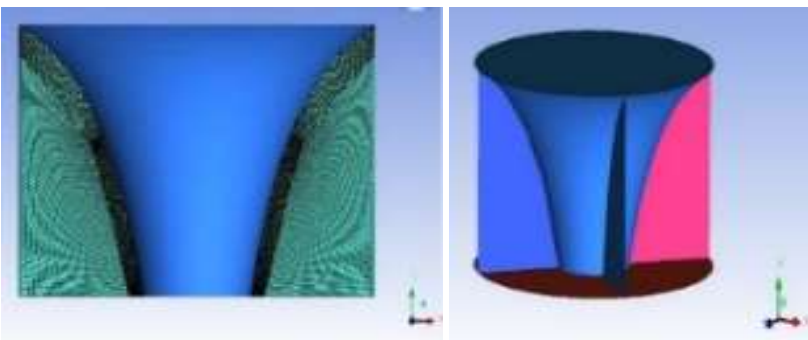

Fig. 4 - Wind Capturer Model and Mesh

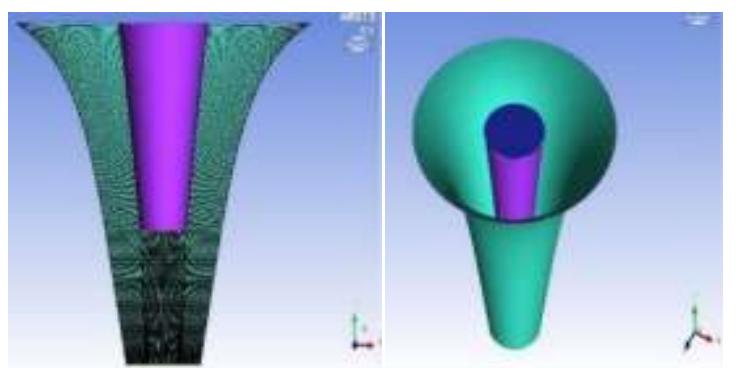

Fig. 5 - Bottom Cone Model and Mesh

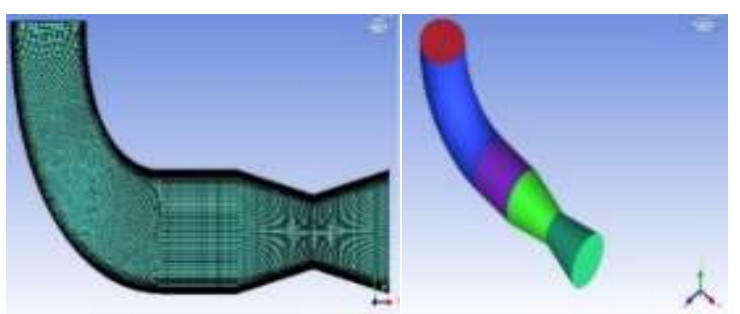

Fig. 6 - Wind Carrier and Accelerator 


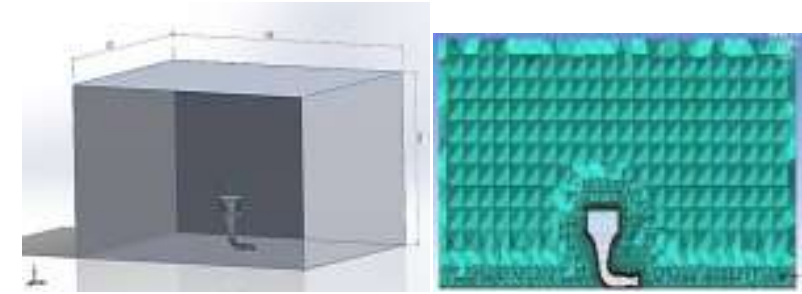

Fig. 7 - External Fluid Domain

\section{BASIC ASSUMPTIONS:}

In order to solve and simplify the problem, following assumptions were made:

$>$ Three dimensional, steady-state formulations are assumed thus no unsteady motion and analysis are involved.

$>$ Uniform and Incompressible fluid flow is assumed.

$>$ Effect of heat and heating in the atmosphere is neglected.

$>$ The surrounding air pressure is considered as 101325 Pa.

$>$ Thickness of the model is neglected i.e. planar 3 dimensional model is assumed.

$>$ Slip wall condition was assigned to the domain walls except the bottom one.

$>$ All the simulations are made by assuming constant free stream velocity throughout the domain.

\section{SOLVER FORMULATION:}

Analysis is carried out with pressure based, absolute velocity and steady state solver. Therefore model doesn't include the unsteady motion of INVELOX system. Three dimensional Reynolds - Averaged Navier - Stokes equation (RANS) equations were solved numerically with a second order accuracy upwind schemes and standard $\kappa-\epsilon$ turbulence closure with standard wall functions. A constant input velocity field, representing the free stream wind, was assigned to the entire frontal plane of the flow domain. Under - Relaxation factors taken for the present work is shown in the table below. Convergence criteria are set to $10^{-}$ ${ }^{6}$ for $\mathrm{x}$ - velocity, $\mathrm{y}$ - velocity, $\mathrm{z}$ - velocity and $10^{-5}$ for $\kappa$ and epsilon. Under solution methodology, SIMPLE scheme is adopted for pressure - velocity compounding and for spatial discretization least squares cell based is adopted.

\section{GRID INDEPENDNCE TEST:}

It is a very important step to decide the optimum mesh number and size for obtaining accurate results with minimum computational time and acceptable result with minimum error in the solution. In the present work, parameter considered for the grid independency test is the speed ratio. The grid elements were increased from 2.88 million to 13.27 million. The run time was more than 2 days for each simulation as the elements crossed 10 million counts. But the accuracy is of more importance than all other things. Solution attained a stable result with very minimal error at the mesh count of 11.03 million. So this mesh size is chosen as the optimum size and all the simulations are run after meshing the elements to near this count so that the result is dependable. Following figure shows the graph plotted with speed ratio against the mesh count.

\section{RESULTS AND DISCUSSIONS:}

Grid independence study is performed for symmetric configuration of INVELOX i.e. for 4 guide blade configuration with blade angle $45 \mathrm{deg}$. Blade angle is defined as the angle between the reference guide blade (one of the 4 blades) and the wind flow direction. The speed ratio obtained is 1.84, mass flow rate is $39.5 \mathrm{Kg} / \mathrm{s}$ and average velocity at the Venturi is $12.31 \mathrm{~m} / \mathrm{s}$. So the result matches with very minimal error. It becomes wrong to conclude results at this point because this system has to be tested for all the blade angles i.e. omnidirectional property and for various speeds.

\section{CASE 1) OMNIDIRECTIONAL PROPERTY:}

Wind capturer is adjusted for different blade angles and tested instead of changing the flow direction and model. Results obtained are satisfactory because the variations are very less. Speed ratio varies in between 1.84 and 1.91, mass flow rate in between $39.5 \mathrm{Kg} / \mathrm{s}$ to $41.25 \mathrm{Kg} / \mathrm{s}$ and the average velocity at Venturi in between $12.31 \mathrm{~m} / \mathrm{s}$ to 12.84 $\mathrm{m} / \mathrm{s}$.

\section{CASE 2) FOR VARIOUS SPEEDS:}

As claimed by the SHEERWIND, INVELOX has the ability to produce the power at low wind speeds. This property needs to be tested. Following graph shows the speed ratio plot for different wind speeds. It is found that INVELOX performs satisfactorily up to speed $1 \mathrm{~m} / \mathrm{s}$. Speed ratio at 1 $\mathrm{m} / \mathrm{s}$ free stream velocity is 1.62 .

\section{CASE 3) 3 GUIDE BLADECONFIGURATION}

With the idea of increasing the amount of air captured 3 symmetric guide blades are selected because sweep angle i.e. angle between two successive blades is increased to $120 \mathrm{deg}$.After simulation it is found that for blade angle $60 \mathrm{deg}$ the amount of air captured increased. Speed ratio achieved is 1.9. But when the system is tested for Odeg blade angle speed ratio dropped to 1.55 as the guide blades failed to obstruct and direct the wind inside the tapered cone. System performs satisfactorily in between $15 \mathrm{deg}$ to $105 \mathrm{deg}$ blade angle but fails for $0 \mathrm{deg}$ to $15 \mathrm{deg}$ and $105 \mathrm{deg}$ to $120 \mathrm{deg}$ blade angle as seen from graph. So the system is not omnidirectional. But in future if the system is used for unidirectional application then 3 blade guides can be preferred over 4 guide blade configuration.

\section{CASE 4) EXTENDED GUIDE BLADES:}

Analyzing the flow inside the INVELOX it is observed that only a small part of captured air is passed on to the tapered cone remaining air escaped through the space beneath guide blades as clearly seen in stream line plot colored by velocity In order to reduce this loss guide blades are extended inside the annular tapered cone. For analyzing the effect, guide blades are extended in steps of $1 \mathrm{~m}$ until it reaches the bottom of top cone. 
It is found that there is no appreciable change in the mass of air captured initially when the extension is $1 \mathrm{~m}$. After that it increases till $3 \mathrm{~m}$ extension. For $3 \mathrm{~m}$ extension speed ratio is 1.88 which is $2.17 \%$ higher than the previous configuration. Mass flow rate is $40.6 \mathrm{Kg} / \mathrm{s}$ and the average velocity at the Venturi is $12.64 \mathrm{~m} / \mathrm{s}$.

But extending the guide blades till the bottom of inner cone resulted in performance deterioration. Speed ratio dropped to 1.65 , mass flow rate to $35.69 \mathrm{Kg} / \mathrm{s}$ and average velocity at Venturi to $11.11 \mathrm{~m} / \mathrm{s}$. This drop in performance can be attributed to the decreased flow area at the double nested tapered cone. As the guide blades are extended the cross sectional area available for the flow keeps on reducing as the cones are tapered. This affects the upstream flow and causes the wind upstream to reduce the velocity of wind approaching the system. This it can be concluded that extending the blades up to $2 \mathrm{~m}-3 \mathrm{~m}$ increases the amount of air being captured.

Power generated is given by,

$\mathrm{P}=\frac{1}{2} C_{p} \rho A V^{3}$

Where, $\mathrm{P}$ - Power Obtainable $(\mathrm{W}), C_{p}$ - Co-efficient of Performance, $\quad \rho$-Density of Air $\left(\mathrm{Kg} / \mathrm{m}^{3}\right), \quad$ A Sweep area of wind turbine $\left(\mathrm{m}^{2}\right), \mathrm{V}-$ FreeStream Velocity $(\mathrm{m} / \mathrm{s})$

Let's consider the efficiency $(\eta)$ of the turbine to be $30 \%$. Without extended guide blades average velocity at Venturi is $12.31 \mathrm{~m} / \mathrm{s}$ and with extended guide blades up to $3 \mathrm{~m}$ average velocity at Venturi is 12.64 .

Case (i): Density of air $(\rho)=1.225 \mathrm{Kg} / \mathrm{m}^{3}$

$$
\text { Area }(\mathrm{A})=\frac{\pi}{4} d^{2}=\frac{\pi}{4} * 1.31^{2}=1.3478 \mathrm{~m}^{2}
$$

Freestream velocity $\left(\mathrm{V}_{1}\right)=12.31 \mathrm{~m} / \mathrm{s}$

$$
\begin{gathered}
P_{1}=\frac{1}{2} * \eta * \rho * A * V_{1}{ }^{3} \\
P_{1}=\frac{1}{2} * 0.3 * 1.225 * 1.3478 * 12.31^{3} \\
\boldsymbol{P}_{1}=461.98 \mathrm{Watts}
\end{gathered}
$$

Case (ii): Freestream velocity $\left(\mathrm{V}_{2}\right)=12.64 \mathrm{~m} / \mathrm{s}$

$$
\begin{gathered}
P_{2}=\frac{1}{2} * \eta * \rho * A * V_{2}{ }^{3} \\
P_{2}=\frac{1}{2} * 0.3 * 1.225 * 1.3478 * 12.64^{3} \\
P_{2}=\mathbf{5 0 0 . 1 4 W a t t s}
\end{gathered}
$$

Percentage increase in the power $=\frac{P_{2}-P_{1}}{P_{1}} * 100 \%$ $=\frac{500.14-461.98}{461.98} * 100=8.26 \%$

\section{CONCLUSION:}

The fluid flow analysis is carried out in the present work using the commercially available CFD tool ANSYS FLUENT, along with the validation. Hybrid mesh was adopted. A successful validation for speed ratio is obtained with less than $3 \%$ error. Following conclusions are made after studying the different cases:

- It is shown that INVELOX can be designed to capture and accelerate air using an omnidirectional intake.
- The system has low sensitivity with respect to the wind direction.

- $\quad$ The system gives satisfactory results for speeds up to 1 $\mathrm{m} / \mathrm{s}$.

- System with 3 guide blades doesn't give omnidirectional performance.

- This configuration can be used for unidirectional applications.

- For the 4 guide blade design, extending the guide blades in to the lower cone up to $2 \mathrm{~m}-3 \mathrm{~m}$ results up to $3 \%$ increase in the speed ratio.

- With $2.17 \%$ increase in the speed ratio,8.26\% increase in power generation can be achieved.

\section{REFERENCES:}

[1]. INVELOX: Description of a new concept in wind power and its performance evaluation by Daryoush Allaei, Yiannis Andreopoulos.

[2]. Allaei D. Using CFD to predict the performance of innovative wind power generators.

[3]. Grant A, Kelly, N. The development of a ducted wind turbine simulation model.

[4]. Allaei D. Turbine-intake tower for wind energy conversion systems. US patent no. 7,811,048; 2010

[5]. SorensenJN. Aerodynamic aspects of wind Energy conversion. Annual Rev Fluid Mech 2011.

[6]. Al-Bahadly IH, Petersen AFT. A ducted horizontal wind turbine for efficient generation.

[7]. Allaei D. Power generating skin structure and power generation system thereof. US patent no. 7,812,472.

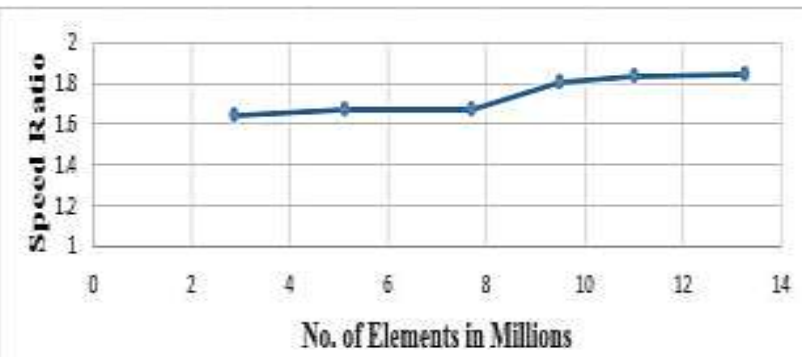

Graph1 - Grid Independence Study for Speed Ratio

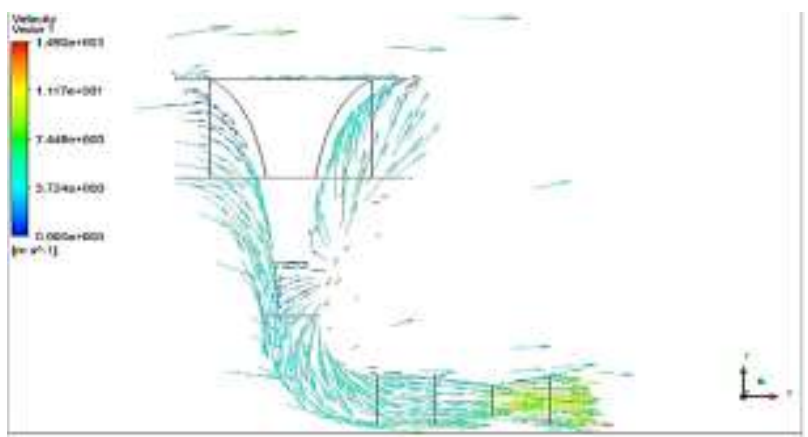

Fig. 8 - Velocity vector along mid-z plane. 


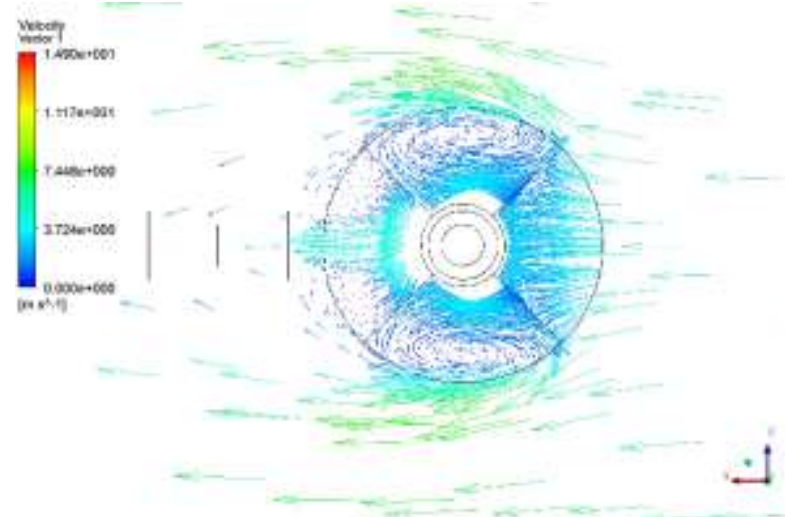

Fig.9 - Velocity vector along x-z plane

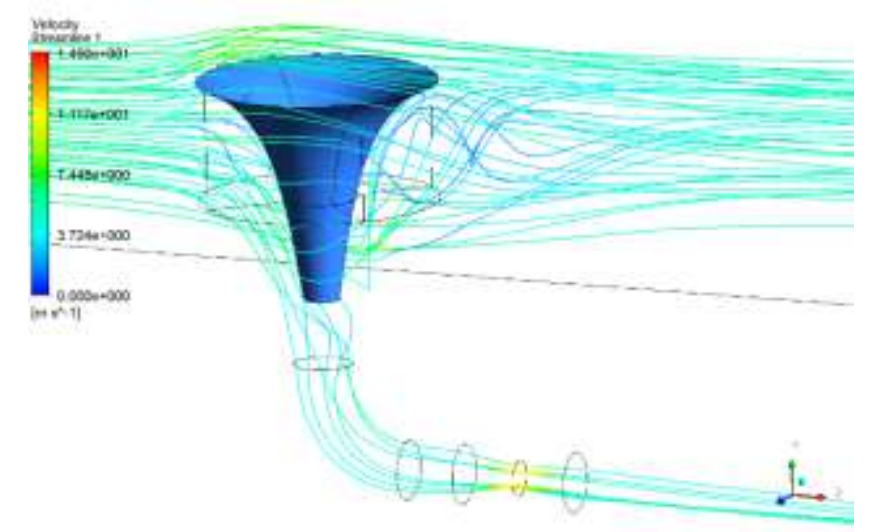

Fig. 10 -Streamline colored by velocity

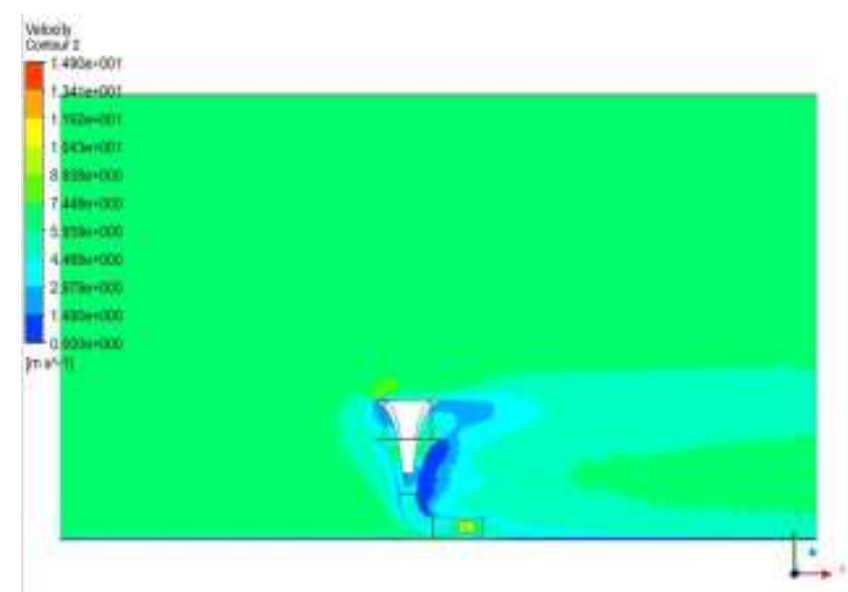

Fig. 11 -Velocity contour along mid z plane.

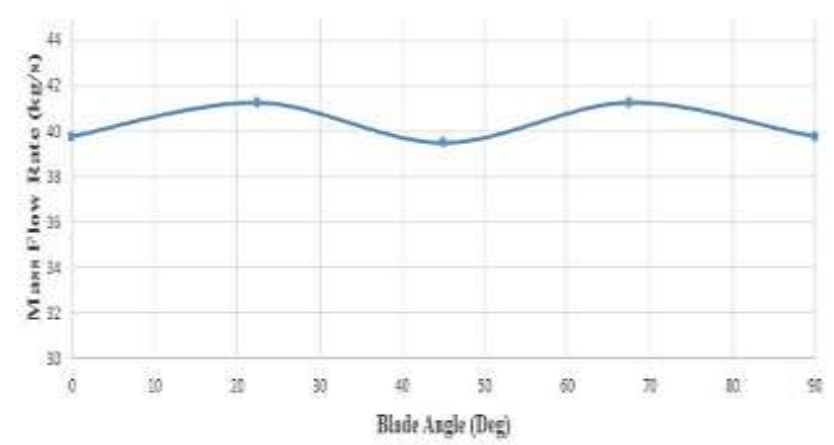

Fig. 12 - Performance study for different blade angle.

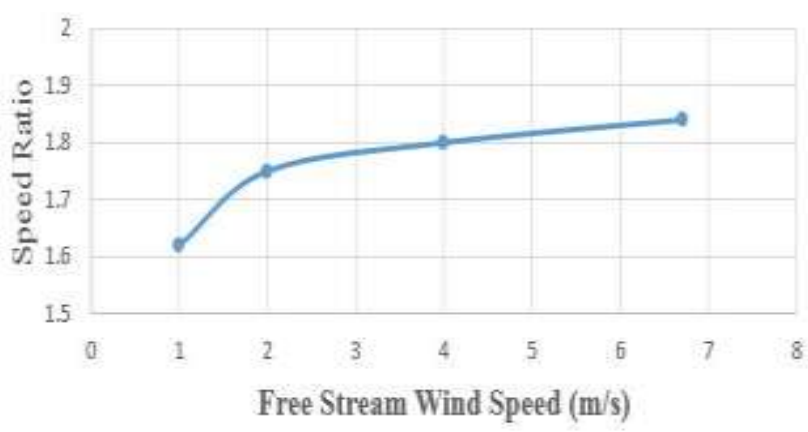

Fig. 13 -Performance study under different wind speeds.

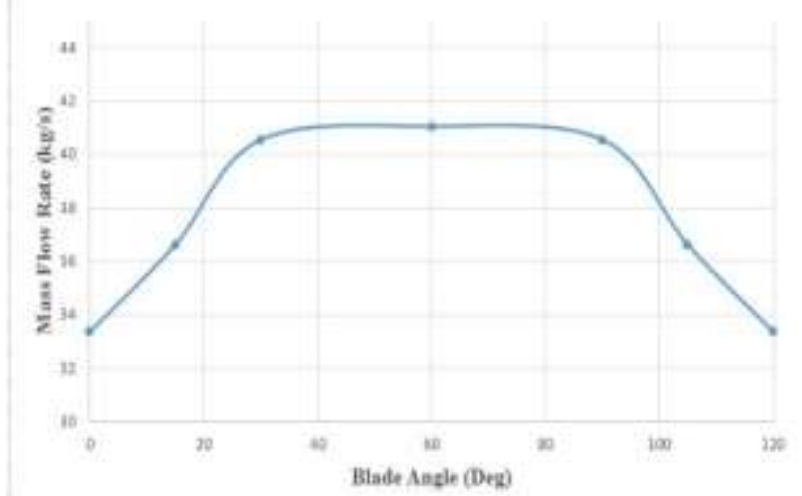

Fig.14 - Performance study for 3 guide blade configuration
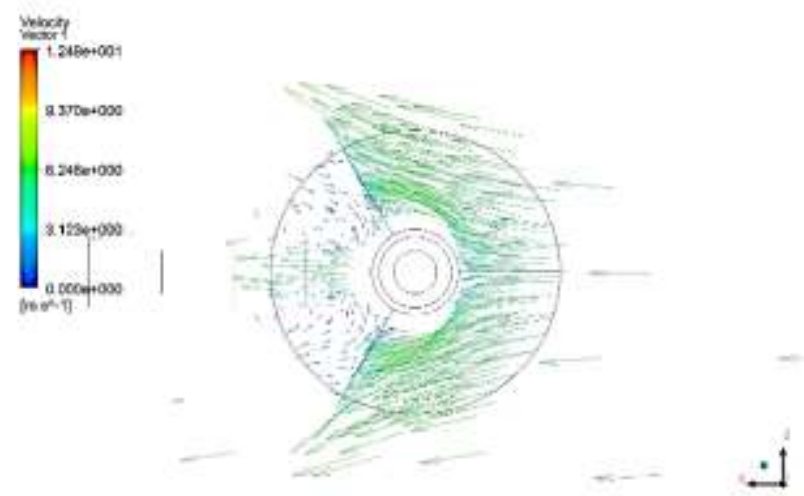

Fig. 15 - Velocity vector for 3 guide blades along x-z plane

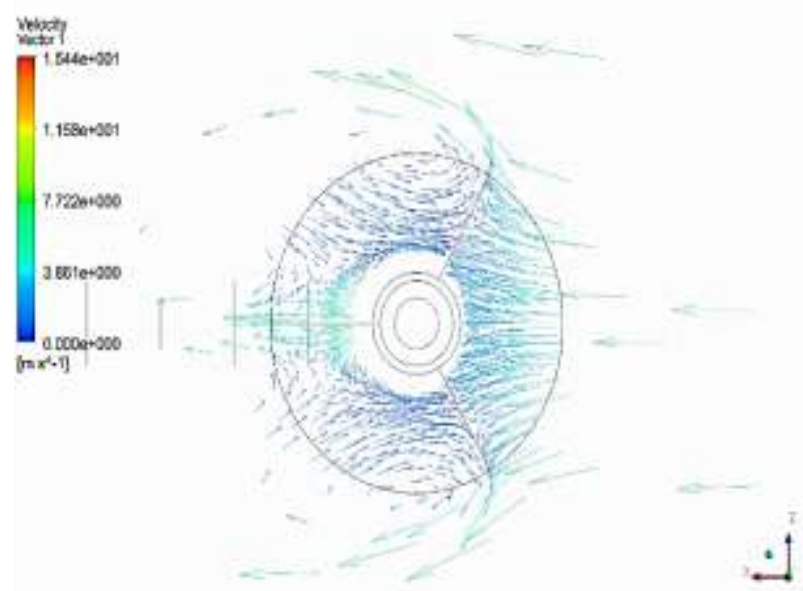

Fig. 16 - Velocity vectors for 60deg blade angle 


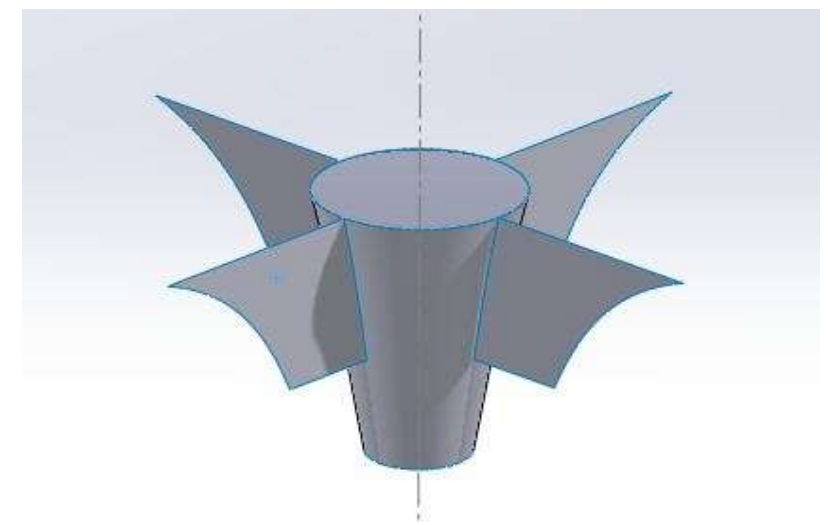

Fig. 17 -Extended guide blades (3m)
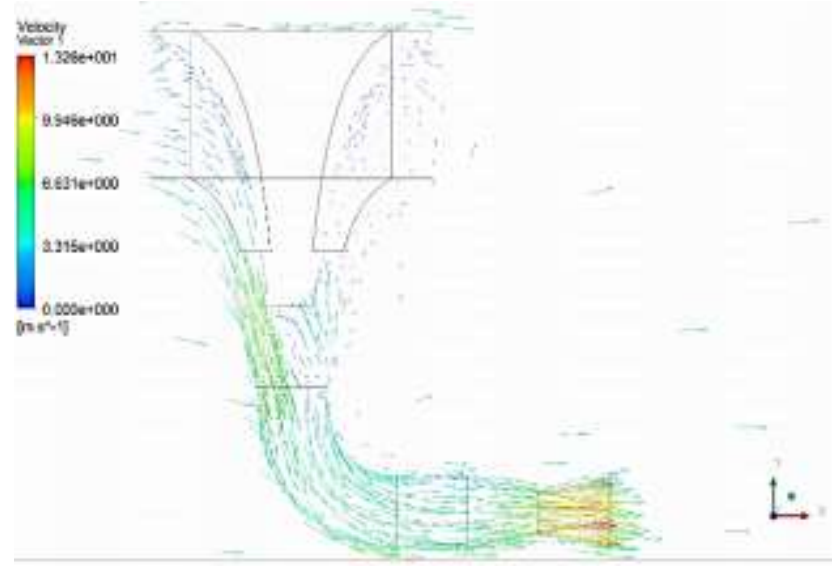

Fig. 18 -Velocity vectors along mid z plane

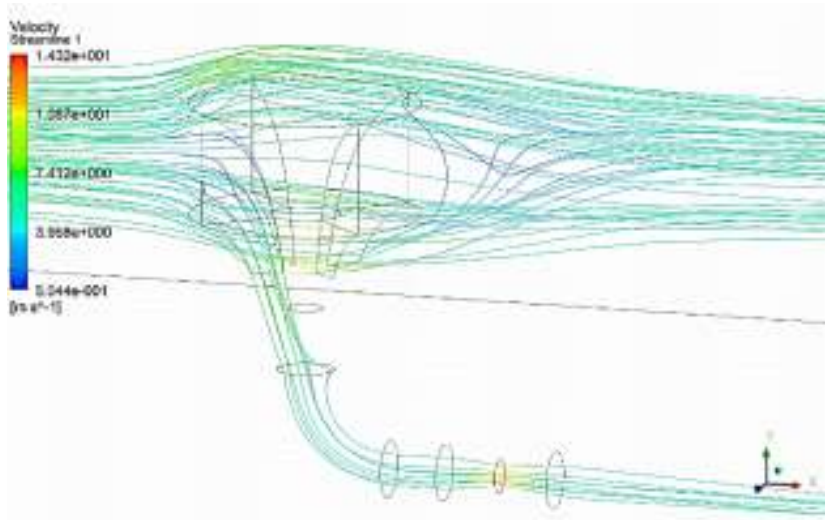

Fig. 19 - Streamlines colored by velocity

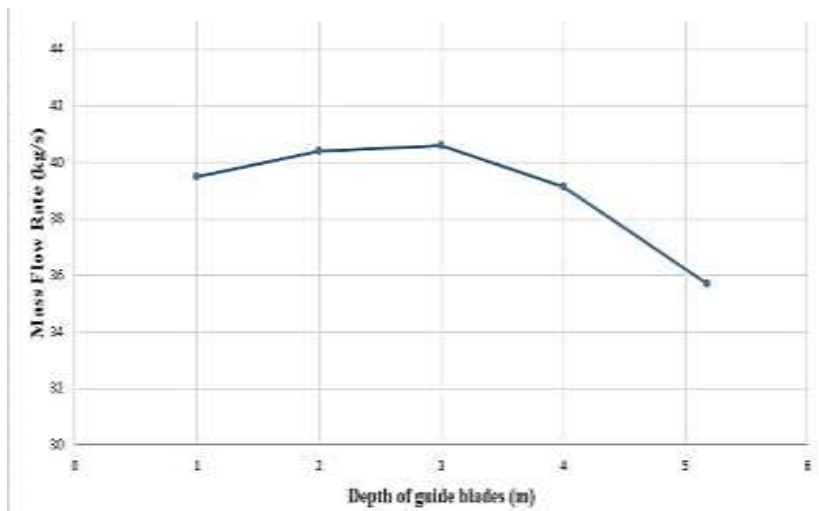

Fig.20 - Performance study for different depth of guide blades. 